
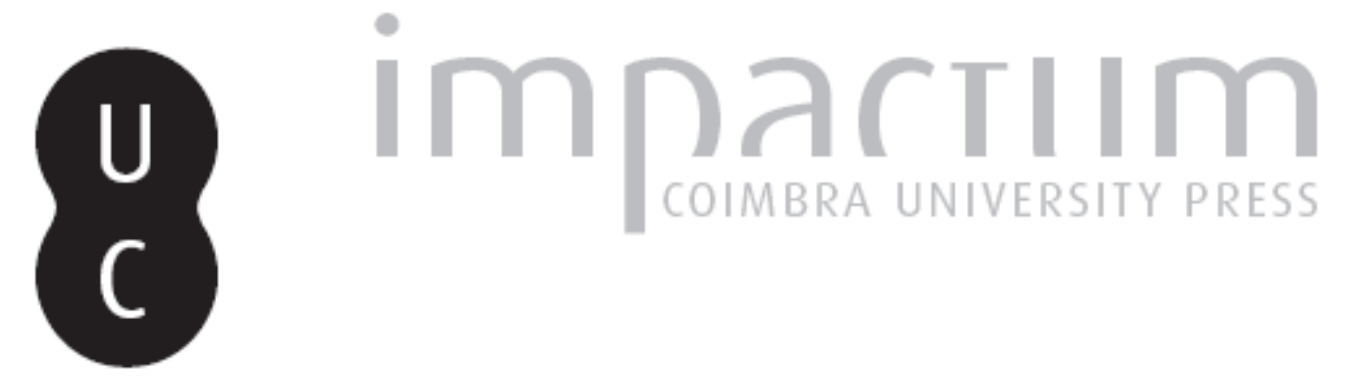

\title{
Narcissus Circaeus ou o trágico em II Compleanno de Marco Filiberti
}

Autor(es): $\quad$ Rodrigues, Nuno Simões

Publicado por: Imprensa da Universidade de Coimbra

URL persistente:

URI:http://hdl.handle.net/10316.2/41487

DOI:

DOI:https://doi.org/10.14195/0872-2110_60_14

Accessed : $\quad$ 26-Apr-2023 13:52:48

A navegação consulta e descarregamento dos títulos inseridos nas Bibliotecas Digitais UC Digitalis, UC Pombalina e UC Impactum, pressupõem a aceitação plena e sem reservas dos Termos e Condições de Uso destas Bibliotecas Digitais, disponíveis em https://digitalis.uc.pt/pt-pt/termos.

Conforme exposto nos referidos Termos e Condições de Uso, o descarregamento de títulos de acesso restrito requer uma licença válida de autorização devendo o utilizador aceder ao(s) documento(s) a partir de um endereço de IP da instituição detentora da supramencionada licença.

Ao utilizador é apenas permitido o descarregamento para uso pessoal, pelo que o emprego do(s) título(s) descarregado(s) para outro fim, designadamente comercial, carece de autorização do respetivo autor ou editor da obra.

Na medida em que todas as obras da UC Digitalis se encontram protegidas pelo Código do Direito de Autor e Direitos Conexos e demais legislação aplicável, toda a cópia, parcial ou total, deste documento, nos casos em que é legalmente admitida, deverá conter ou fazer-se acompanhar por este aviso.

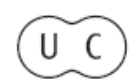


COIMBRA • 2015

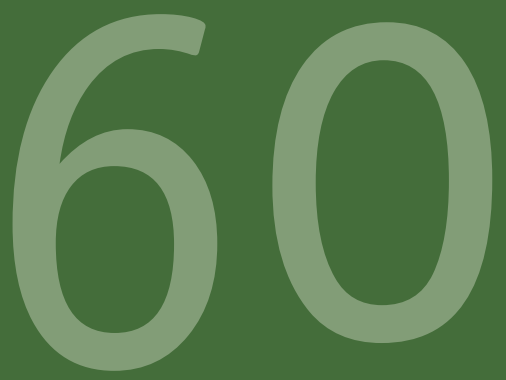

\title{
BOLETIM DE
}

\section{ESTUDOS CLÁSSICOS}

\author{
ASSOCIAÇÃO \\ PORTUGUESA \\ DE ESTUDOS \\ CLÁSSICOS \\ INSTITUTO \\ DE ESTUDOS \\ CLÁSSICOS
}




\title{
NARCISSUS CIRCAEVS OU O TRÁGICO EM IL COMPLEANNO DE MARCO FILIBERTI
}

\section{NARCISSUS CIRCAEVS OR THE TRAGIC IN IL COMPLEANNO BY MARCO FILIBERTI}

\author{
NUNO SIMÕES RODRIGUES \\ UNIVERSIDADE DE LISBOA \\ CH-UNIVERSIDADE DE LISBOA/ CECH-UNIVERSIDADE DE COIMBRA \\ nonnius@letras.ulisboa.pt
}

Resumo: Matteo e Francesca e Shary e Diego constituem dois casais amigos, quarentões, que decidem passar um Verão juntos, numa casa de praia no sopé do Monte Circeu, em Itália. O segundo casal tem um filho, David, que está de regresso dos Estados Unidos, para celebrar o seu aniversário com a família. Quando chega, o jovem David depara com duas relações em crise, uma desgastada pelo afastamento dos cônjuges, a outra pela rotina do casal. Mas é a Matteo, o amigo dos pais de David, que cabe entrar num dilema interno que afecta a sua estabilidade emocional e que o atira para o domínio do tabu a vários níveis. Matteo sente-se profundamente atraído pelo jovem David, que, no entanto, parece oscilar entre a obsessão por si próprio e a atenção que o homem mais velho lhe dedica. A Matteo resta decidir se cede à tentação ou se lhe resiste. O certo é que, cedendo à passio, haverá que lidar com as consequências da decisão que farão entrar todos os caracteres numa espiral de tragédia de contornos euripidianos e senequianos, em que não faltam muitos outros ecos da nossa herança 
clássica. São precisamente esses contornos que esta comunicação pretende analisar.

Palavras-chave: Tragédia grega e cinema; Aristóteles; Poética; Trágico; Marco Filiberti.

Abstract: Matteo \& Francesca and Shay \& Diego are two friend couples, in their forties, who decide to spend a summer together, in a beach house at the foot of Mount Circeo, in Italy. The second couple has a son, David, who has returned from the United States to celebrate his birthday with family. When he arrives, the young David faces two relationships in crisis: one worn by the physical separation of the spouses, the other by the routine of the couple. But it's Matteo, David's parents friend, who enters an internal dilemma that affects their emotional stability and that throws him into the domain of the taboo at various levels. Matteo feels deeply attracted by the young David, who, however, seems to oscillate between the obsession with himself and the attention that the older man dedicates to him. Matteo must decide whether he yields to temptation or resists it. The fact is that, yielding to the passio, he will have to deal with the consequences of his decision, which will cause all characters getting into a spiral of tragedy with euripidean and senequian features, in which there is no lack of many other echoes of our classical heritage. It is precisely these features that this paper aims to analyze.

Keywords: Greek Tragedy and Cinema; Aristotle; Poetics; Tragic; Marco Filiberti.

O mar está calmo. Aliás, o Mediterrâneo mantém-se calmo ao longo de toda a película, contrastando com o turbilhão de emoções que perpassa o espírito de cada personagem. 0 mythos que está na base de Il Compleanno, filme realizado por Marco Filiberti em 2009, é relativamente simples, como recomendaria, aliás, Aristóteles: dois casais de meia-idade, Matteo (Massimo Poggio) e Francesca (Maria de Medeiros) e Diego (Alessandro Gassman) e Shary (Michela Cescon) são amigos 
de longa data e decidem passar o Verão juntos, numa casa alugada na costa do Lácio, no sopé do Monte Circeu. Ambos os casais têm filhos. Matteo e Francesca têm uma menina ainda pequena, Elena (Karen Ciaurro); Diego e Shary são pais de David (Thyago Alves), um jovem no final da adolescência, que vive com a mãe nos EUA e que nesse Verão regressa a Itália, pela primeira vez em cinco anos, para celebrar o seu aniversário com a família.

Quando chega, o jovem David depara com duas relações em crise, uma - a dos seus pais - desgastada pelo afastamento físico e psicológico dos cônjuges; a outra - a dos amigos - esboroada pela rotina do casal. Mas é a Matteo, o psicanalista amigo dos pais de David, que cabe entrar num dilema interno que afecta a sua estabilidade emocional e que lançará todos no abismo. Matteo sente-se profundamente atraído pelo jovem David, que, no entanto, parece oscilar entre a obsessão por si próprio e a atenção que o homem mais velho lhe dedica. A Matteo resta decidir se cede à tentação proibida ou se lhe resiste. Ao fim de alguns dias de convívio, em que momentos de diversão e de descontracção são entrecortados por fases de conflito, angústia e nostalgia (que se percebe numa constante alusão das personagens de meia-idade aos seus tempos de juventude, representados sobretudo pela música que então escutavam), o espírito de Matteo cede e, encorajado por David, acaba por se macular com o tabu e consumar o adultério com o adolescente, como se de uma peripécia e catástrofe trágicas se tratasse.

Tudo acontece no próprio dia de aniversário do rapaz, para o qual a acção converge, num ambiente de festa, qual recurso ao tópico do festim de sangue ou do banquete aziago das literaturas antigas. Nesse dia, nas ruas da vila, surge junto à mãe de David uma mulher de negro, sentada impassível numa escada, qual Parca prenunciadora do que estás prestes a acontecer. Já antes, o mar cuspira o cadáver de uma jovem perante os olhos de Francesca, que naquele momento se apercebe da efemeridade da vida e da própria felicidade. O mar avisa que até de uma aparente calma pode eclodir a tragédia. 
Em fundo, ouve-se o final do I acto de Tristão e Isolda e Matteo e David são apanhados em flagrante por Francesca, que chega no momento errado. Desvairada, a mulher sai de casa e lança-se numa fuga descontrolada, acabando por ser colhida por um automóvel que a mata instantaneamente. Com a transgressão de Matteo e David, a tragédia consuma-se na pessoa de Francesca, a inocente que culmina com a vida o horror provocado pela cena que presenciou. A transgressão de Matteo teve consequências para si e para os seus e nenhum deles voltará a ser quem era.

Um dos aspectos relevantes deste filme é a sua inter-meta-textualidade. Qualquer espectador minimamente inteirado da História do Cinema reconhecerá de imediato na película as evidentes reminiscências de L. Visconti e da sua adaptação de 1971 de Der Tod in Venedig de Thomas Mann (pub. 1912). O filme de Visconti retrata a visita de Gustav von Aschenbach à cidade de Veneza, no início do século XX. Aschenbach (Dirk Bogarde) é um escritor/compositor de meia-idade, obcecado pela beleza e juventude de Tadzio (Björn Andresen), com quem, todavia, nunca fala ou em quem nunca toca, havendo entre as personagens uma mera interacção tácita. Reconhece-se, aliás, no processo narrativo, uma alusão ao amor teorizado por Platão no Banquete e no Fedro, a que se juntam evidentes influências nietzschianas, presentes na tensão apolínea e dionisíaca que se faz sentir no interior do espírito do artista. A agonia em que se mantém e a destruição para que caminha encontra paralelo metafórico na ruína da própria Veneza, que sucumbe a uma epidemia de cólera e que acabará por matar o próprio Aschenbach. No filme de Visconti, também o Adriático se mantém calmo, o que não significa, porém, que não prenuncie a morte que se espalha por toda a cidade. A resistência também destrói. Veja-se Hipólito...

A essência ou ponto de partida de Il compleanno é a mesma de Morte a Venezia. Um homem de meia-idade revela-se totalmente cego de paixão por um adolescente, que agora não é um mero desconhecido, mas alguém próximo, o filho dos seus melhores amigos. Os ecos do filme de Visconti 
estão lá e são perfeitamente reconhecíveis. A título de exemplo, citaríamos a utilização da música, poderosíssima em ambos os casos. No primeiro, o recurso de Visconti ao Adagietto da $5^{\text {a }}$ Sinfonia de G. Mahler (1902, que torna o filme inesquecível para o seu espectador), com que abre e fecha a película; no segundo a utilização da música de Tristan und Isolde de R. Wagner (1859), que tem também a função de anunciar a tragédia a que vamos assistir. A primeira sequência do filme, cuja primeira imagem é precisamente o mar, é mesmo o final do $1^{\circ}$ acto da ópera de Wagner a que os dois casais assistem e, nela, ouvimos Francesca ler, no programa do espectáculo: tudo «caminha para a morte» e, desde logo, Matteo sente-o...

Mas enquanto o filme de Visconti, na linha do romance de Mann e independentemente do desfecho, é sobretudo uma brilhante reflexão sobre a filosofia platónica, o filme de Filiberti é a negação da mesma, enveredando pela queda do herói e pela submissão à paixão que o dilacera. Assim, o Matteo de Filiberti acaba por se revelar um herói trágico, com muitas das características que os Antigos para ele definiram, repudiando o herói filosófico teorizado pelos textos de Platão. Longe de qualquer tipo de platonismo, Matteo revela-se carnal, quase selvagem e satírico, «dionisíaco» na concretização da sua sexualidade, e essa característica é simultaneamente causa e sintoma da tragédia em que cairá.

Marco Maria Filiberti é um músico, actor e realizador italiano, nascido em Milão e licenciado em História do Teatro pela Università degli Studi di Milano, o que deverá explicar muitas das suas opções dramatúrgicas e narrativas. Com efeito, à escolha do que poderíamos classificar como uma tragédia burguesa para enredo de Il Compleanno não deverá ser estranho o percurso académico do seu realizador.

Filiberti estreou-se em 2001 com Vespero a Tivoli, uma curta-metragem com a qual começou desde logo a angariar prémios e reconhecimento em vários foros cinematográficos internacionais. Assim aconteceu com Il Compleanno que, entre outros, foi galardoado com o prémio de Melhor Filme do Festival de Cinema Italiano ad Ajaccio e o prémio do público no Tierra di Siena Film Festival. 
O enredo do filme gira em torno de cinco personagens essenciais (dois casais e o filho de um deles), a quem se junta uma galeria de outros caracteres, que arrastam consigo histórias paralelas mas que na verdade pouco ou nada acrescentam ao fio que a trama desenvolve.

Matteo é o centro de tudo. Self made man, o psicanalista que conquistou a pulso o lugar que alcançou no plano social e económico, Matteo é um homem comum, o burguês cuja vida e desejo de nela vencer não lhe terá dado tempo ou espaço para pensar sobre si mesmo. Casado, pai de uma filha, detentor de uma carreira invejável, Matteo tem o seu mundo ordenado e politicamente correcto. Mas um dia acorda como se estivesse num mar falsamente calmo, numa vida que entretanto passou. Parece ser a imagem de David, emergente das águas (o David de Filiberti emerge continuamente das águas) que reflectem um corpo que é a imagem de juventude, beleza e perfeição, sugerindo a eternidade imaculada de uma divindade grega, que desperta a consciência de Matteo para essa realidade. Há, aliás, no nome e no corpo do jovem algo de evocativo da obra-prima neoclássica de Miguel Ângelo, em que predominam precisamente a juventude e a beleza física. Doravante, Matteo estará preso à imagem de David, que passa assombrar os seus dias e as suas noites até ao precipício.

Mas se Matteo parece ser de início o homem perfeito, Diego, o pai de David, padece do «complexo de Peter Pan»1, o homem que se recusou a crescer, imaturo, irrealizado, irresponsável. O contraste entre as duas personagens é claro e parece haver mesmo pela parte de David a procura, em Matteo, do pai que Diego não foi para ele. Em contrapartida, em David, Matteo parece procurar-se a si próprio e a sua juventude perdida. Não será por acaso que Filiberti põe Matteo a ler Proust, trazendo-nos de imediato à memória o seu À la recherche du temps perdu, onde os temas homoeróticos têm um papel significativo. David parece ser também a chave que libertará Matteo dos grilhões que

\footnotetext{
${ }^{1}$ Ver e.g. Kiley 1983.
} 
o prendem à família. Note-se como ele se comporta quando, de forma pueril e saboreando um efémero momento de liberdade, os dois homens passeiam de motorizada pelas estradas da costa italiana, contornando o mar, desprovidos de qualquer tipo de segurança. É como se Matteo se reencontrasse. Seguindo uma linha freudiana (e não deverá ser por acaso que Matteo é psicanalista), essa busca paterna ou do próprio eu confundir-se-á entre os afectos, e a sexualidade intrometer-se-á entre os dois homens de forma irremediável.

Shary, a mãe de David, preferiu o distanciamento físico e por consequência psicológico, instalando-se nos EUA e investindo todo o seu amor no filho único. Shary pressente a tensão, sobretudo em Matteo, mas falhará em perceber a essência do que se passa à sua volta. Para ela, aliás, o verdadeiro, se não único, problema é o "omniausente» Diego. O confronto com o marido traz à tona todos os desaires das escolhas passionais de Shary.

E depois há Francesca. Francesca assiste impotente às transformações na personalidade do marido, Matteo, que o levam a ter reacções inusitadas e que ela desconhecia. Para Francesca, tais comportamentos são variações dependentes da exaustão, do trabalho, da rotina. Francesca acha que a sua vida íntima até corre bem e apenas se preocupa com o quotidiano, com o imediato; é incapaz de ver mais longe. Esse é o seu erro fatal, a sua cegueira, claramente trágica. A mulher está longe de perceber que a crise existencial do marido é bem mais profunda e acabará por ser totalmente enredada na teia que as Meras tecem para estas personagens.

David é um carácter ambíguo. Se por um lado parece ser o jovem inocente e bem parecido que regressa a casa para desestabilizar corações, por outro ele sabe bem o poder que exerce sobre o espírito de Matteo, o que se confirma na cena em que, qual Endímion, emerge das águas reflectindo a luz da lua, para conquistar definitivamente o psicanalista. A partir desse momento, aliás, a tragédia está garantida, faltando apenas o reconhecimento que providenciará o clímax que se manifestará na morte de Francesca. A manipulação que David faz de 
Matteo, e a que este sucumbe, encontra eco na cena em que o jovem se auto-satisfaz sexualmente (o tema reaparecerá, dessa vez com Matteo, numa clara evocação de American Beauty, de Sam Mendes, confirmando a inter-metatextualidade do filme ${ }^{2}$ ), ao mesmo tempo que ouve a música do tempo dos pais (Maladetta Primavera interpretado por Loretta Goggi), e é observado em silêncio, num acto de puro «voyeurismo» de um Matteo profundamente emocionado com a beleza da juventude que tem perante os seus olhos, mas também com a nostalgia do tempo perdido.

David proclama a adoração do próprio corpo, qual Narciso da Antiguidade. Como acontece com essa personagem, no jovem há o excesso, a hybris, que se manifesta a paixão que aparenta ter por si próprio. Em David, como em Narciso ou em outras personagens da mitologia grega, a beleza é uma maldição. O Narciso que há em David agride e provoca a fatalidade em que a vida de Matteo se transformou e que ameaça esvair-se, sem que o psicanalista se tenha realizado em pleno.

Com efeito, as formas que Filiberti escolhe para dar corpo às emoções que as suas personagens vivem e experienciam são marcadamente greco-romanas. A Antiguidade Clássica é, aliás, explícita ou implicitamente omnipresente no filme, que transpira a Grécia e Roma. Desde logo o cenário em que toda a acção se passa (e que corresponde a uma unidade de acção, de lugar e de tempo - marcada pelas personagens que se movem em círculo fechado, na casa da praia). As costas do Circeu remetem para a Odisseia de Homero, bem como a alusão à própria Circe e a Ea, a ilha da feiticeira homérica, que Matteo contempla; as referências que o psicanalista encontra no guia turístico sobre o passado clássico da estância em que se encontram; a professora de latim, que personifica os conflitos familiares inerentes à tragédia grega, mas também a perenidade dos valores clássicos que contrasta com a

\footnotetext{
${ }^{2}$ Numa outra sequência, a presença dos marinheiros e a miragem de David vestido como um deles parece evocar a versão cinematográfica do romance de Jean Genet, Querelle de Brest (1947). A adaptação ao cinema foi feita em 1982, por Rainer Werner Fassbinder e contou com as interpretações de Brad Davis, Jeanne Moreau e Franco Nero.
} 
futilidade da vida contemporânea simbolizada por um livro de poesia latina por abrir; ou a escolha do nome «Aurora», a Eos eternamente apaixonada dos Gregos, para a jovem enamorada de David ${ }^{3}$.

Mas a maioria dessas referências é subliminar e apenas acessível a um público capaz de entender um segundo nível de leitura e códigos menos evidentes. Consideramos mesmo que tais elementos funcionam como estrutura de base em que assenta a própria narrativa. Desde logo, há a dialéctica espírito/corpo, a que já aludimos, e que parece remeter para uma rejeição do platonismo em que o amor é sobretudo contemplado.

Mas há também o androerotismo que dá sentido à composição do carácter de David. A valorização do corpo masculino é claramente um tópico clássico, bem como a relação que se estabelece entre Matteo, um homem maduro e barbado, e David, um jovem adolescente e imberbe. Parece-nos impossível não entrever nesta relação o topos do erastes e do eromenos que consubstanciava a pederastia grega nos períodos arcaico e clássico ${ }^{4}$. Também os momentos em que o Matteo voyeur se queda observando/contemplando David, que se banha, parecem radicar no famoso mito de Actéon, que aliás pagou caro a ousadia de contemplar o banho de Ártemis 5 .

Por fim, a própria estrutura do enredo, o mythos do argumento, como referimos, cuja praxis se encaminha para a consumação da tragédia que se revela aos olhos de Francesca como se fosse um processo de anagnorisis Numa aparente calma, metaforizada pela tranquilidade de um mar omnipresente e recorrente (abre e fecha o filme) nas imagines que Filiberti nos oferece em contínuo (numa brilhante síntese, Matteo dirá: «eu e o mar»), tudo se desenvolve numa espiral que se torna incontrolável. O locus amoenus que percebemos no mar contrasta com o locus horrendus que Matteo vive no seu interior. A tensão sentida

${ }^{3}$ Sobre Eos, ver e.g. Od. 5.1ss, 121ss.; 4.188; Hes. Theog. 371ss.; 986ss.; Pind. 0. 2.83; Nem. 6.59; Eur. Hipp. 454ss.; Ov. Met. 13.581ss.; 7.690ss.; Hig. Fab. 160, 189, 270.

${ }^{4}$ Ver e.g. Skinner 2010: 119-134, onde lemos uma excelente síntese desta problemática.

${ }^{5}$ Ver Ov. Met. 3.173-252. 
pelas personagens fá-las inclusive transpirar anormalmente, conforme a acção caminha para o seu acme, sob pretexto de um calor cada vez mais intenso. Também aqui a inter-metatextualidade é visível, sendo impossível não pensarmos numa outra tragédia cinematograficamente famosa, o Julius Caesar de Shakespeare visto por Manckiewicz, e na magistral interpretação que Roland Barthes dela fe ${ }^{6}$. Como nota uma das personagens: «coisas horríveis podem acontecer de um momento para o outro».

A cedência de Matteo à paixão que o dilacera é uma hamartia com muito de euripidiano e de senequiano. Há, aliás, em Matteo, algo da Fedra composta pelos poetas evocados. Com a ressalva de a Fedra greco-latina agonizar com uma paixão, independentemente das suas causas ou motivações, sem contudo a concretizar fisicamente. Tal como acontecerá com o Gustav von Aschenbach de Mann. Talvez porque os jovens por si amados não lhes proporcionem essa concretização. A novidade da tragédia deste homem comum, e talvez por isso, está no facto de cair e saciar a carne, pelo menos por momentos. O que não lhe valerá de muito, pois a angústia que se seguirá rapidamente o fará esquecer o prazer efémero. Aliás, a patologia emocional por que Matteo passa terá consequências destrutivas semelhantes às de Fedra e de Aschenbach.

Mas há mais neste Matteo e neste David. É que a tragédia que desencadeiam segue uma linha inaugurada por Eurípides, e em parte seguida por Séneca (e.g. Fedra), e os seus oikeia pragmata ou «temas domésticos» ${ }^{7}$, abalados por violentas paixões e forças exteriores à normalidade do quotidiano, e que virá a ser consolidada pelo teatro moderno e contemporâneo. Também Matteo e os seus companheiros são homens e mulheres que sofrem e que são destruídos nos seus relacionamentos mais íntimos, no seio do próprio sangue ${ }^{8}$. Significa que «a natureza humana é permanente, universal e essencialmente imutável»

\footnotetext{
${ }^{6}$ Barthes 2012: 25-28.

${ }^{7}$ Sousa e Silva 2010: 40.

${ }^{8}$ Williams 2002: 156, 161.
} 
o que faz com que a tragédia se explique «em termos dessa essência humana imutável ou de algumas das suas faculdades» ${ }^{9}$.

Mais na linha de Eurípides do que na de Séneca, contudo, a contemplação da morte de Francesca é-nos subtraída, sendo sugerida apenas pelos sons que ouvimos e confirmada depois pelo corpo sem vida caído no asfalto quente da região do Circeu. A amargura final de Matteo, quando depois da tragédia consumada ele percebe que afinal tudo dependia de si próprio, ilustra bem a afirmação de Raymond Williams: «O que nos espera, no fim do sexo e da feroz e ralada luta pela vida, é a morte. ${ }^{10}$

$\mathrm{Na}$ verdade, estando nós perante um enredo em que um homem violenta a paz e o equilíbrio de uma família (para saciar o seu desejo e finalmente viver aquilo que eventualmente mais queria da vida), em que as suas emoções são desencadeadas pela paixão provocada pelo jovem filho de um casal amigo e os danos colaterais das suas decisões se reflectem na própria mulher e amigos, então talvez as dramatis personae se pudessem originalmente chamar Laio em vez de Matteo, Jocasta em vez de Francesca, Pélops em vez de Diego, Axíoque em vez de Shary e Crisipo em vez de David. Neste ponto, impõe-se mesmo recordar os nossos interlocutores que Eurípides escreveu uma tragédia chamada Crisipo, hoje perdida. Mas parece-nos também que, face a todos estes elementos e aos restantes, de que se destaca um David de contornos narcisistas, nada seria mais adequado do que chamar a esta tragédia clássica moderna Narcissus Circaeus ${ }^{11}$.

${ }^{9}$ Williams 2002: 69-70.

10 Williams 2002: 160.

${ }^{11}$ Texto originalmente apresentado como comunicação ao Congresso Internacional Imagines IV: Sailing in Troubled Waters: O Mediterrâneo Antigo e o seu Legado nas Artes Visuais e Performativas. Universidade do Algarve, 1-4 de Outubro de 2014. 


\section{BIBLIOGRAFIA}

Barthes, B. (2012), «Os Romanos no Cinema», In Mitologias. Lisboa, Edições 70, 25-28.

Kiley, D. (1983), The Peter Pan Syndrome: Men who have never grown up. New York, Dodd Mead.

Skinner, M. (2010), "Alexander and Ancient Greek Society" in P. Cartledge \& F. R. Greenland (eds.), Responses to Oliver Stone's Alexander. Film, History, and Cultural Studies. London, The University of Wisconsin Press, 119-134.

Sousa e Silva, M. F. (2010), «Poeta, criação e público. A noção de trágico nos criadores teatrais atenienses», In Anacleto, M. T., Oliveira, F. M. (orgs.), 0 Trágico. Coimbra, Centro de Literatura Portuguesa, 25-45.

Williams, R. (2002), Tragédia moderna. São Paulo, Cosac \& Naify. 